\title{
SYNCHRONOUS DRIVE OF MACHINES UNIT WITH APPLICATION OF FLOW DIVIDER
}

\author{
Edward Lisowski \\ Pawel Brandys \\ Cracow University of Technology, \\ Institute of Heavy Duty Machines, Poland \\ e-mail: lisowski@astra.mech.pk.edu.pl \\ brandys@astra.mech.pk.edu.pl
}

\begin{abstract}
The paper presents an analysis of control of heavy duty machines unit with hydraulic actuators. Particular the task of analysis of automatic synchronization working movements and positioning has been undertaken. The object of the analysis is hydraulic lifting system with hydraulic actuators in which synchronization is realized by the use of flow divider.
\end{abstract}

Keywords: modeling, simulations, hydraulic drive and control

\section{INTRODUCTION}

There is necessity of synchronization movement of working units in some machine drives. In case when synchronization of piston movement by mechanical connection is difficult applies hydraulic or electrohydraulic synchronizers. The task of assessment of possibilities of achieving required positioning accuracy with the use of flow divider valve has been undertaken in this work. This method of synchronization is relative inexpensive and easy to apply. However, in some working ranges errors in flow dividing are significant what has an influence on positioning accuracy as follows from experimental tests [3]. In order to assessment of possibilities of increasing accuracy a mathematical model of the system has been worked out and the simulations have been carried out.

\section{THE MODEL OF THE SYSTEM}

Simplified diagram of analyzed lifting system is shown in Figure 1. Synchronization of piston movement is realized by the use of two-way flow divider valve 3 . Lifting system is supplied by pump 4. It is pump with variable delivery from 4 to 40 $\mathrm{dm}^{3} /$ min. Control of piston movement is realized by four-way control valve 7 . The system is secured by relief valve 5 in case of excessive increase of pressure. Platform 8 is lifted by four double acting hydraulic cylinders. As simplification it was assumed plane system with two actuators 1 and 2. Load of platform comes from weights of mass $m_{2}$ and $m_{3}$ random distributed on platform and from force $F(t)$, changeable in time.

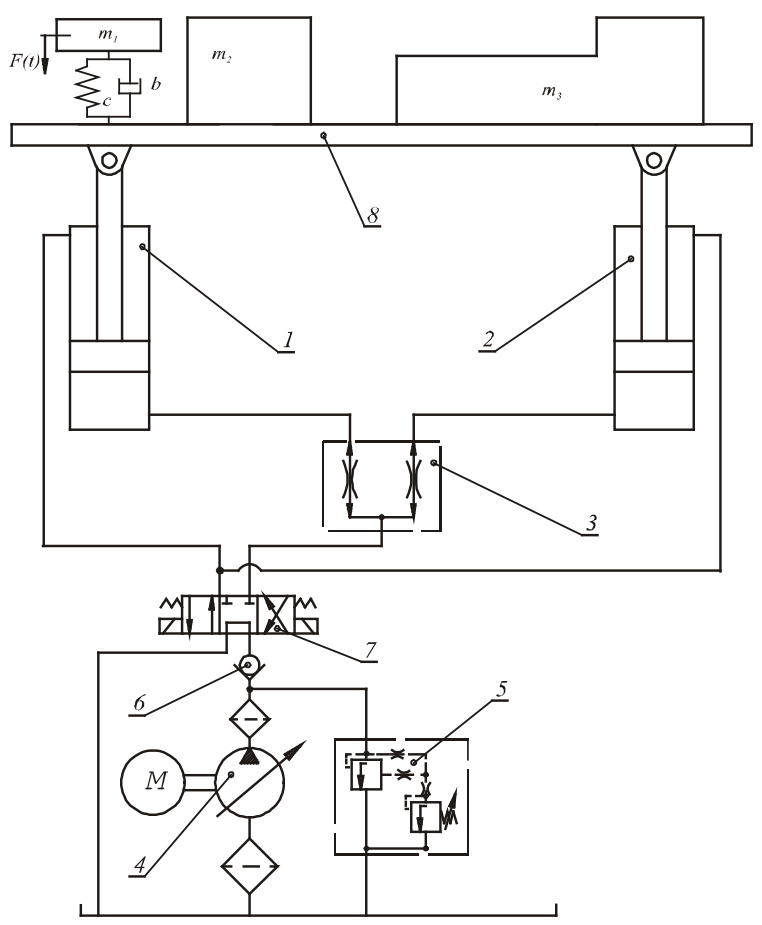

Figure 1. Hydraulic lifting system with flow divider valve: 1, 2 - hydraulic actuators, 3 - flow divider valve, 4 - pump, 5 - relief valve, 6 - check valve, 7 control valve, 8 - platform 
The following simplification were assumed in mathematical model presented in Figure 1:

- valve and system are in thermal equilibrium condition,

- there is no internal and external leakages in the system,

- resistance of fluid flow in valve channels and conduits are negligible,

- particular segments of hydraulic line have constant substitute Bulk modulus,

- valve springs have a linear characteristic,

- the bodies of valves have big stiffness,

- there is no impacts between components of valves and valve-seat,

- a pulsatory way of pump working was omitted,

- physical properties and oil temperature are constant,

- components of the system are inertia less,

- wave phenomena was omitted.

Mass of fluid has been treat like lumped parameter and allocated to characteristic volumes in the system such as: supply line, working volumes of actuators and valve chambers. Cylinder loads has been reduced to piston rod as reduced mass and force.

The following elements of the system were assumed as nonlinear:

- characteristic of supply pump volumetric efficiency,

- characteristic of relief valve,

- characteristic of flow through nozzles and throttle nozzles of flow divider valve,

- hydrodynamic force acting on spool of the flow divider.

With those assumptions equations describing the system are as follows:

- differential equation of flow balance in hydraulic lines,

- equations of flow divider valve,

- differential equations of motion of piston rod and valve components,

- components characteristic,

- control signals and input force.

In order to perform simulations model of the system as block diagrams in Simulink has been worked out. Individual blocks of diagram presented in Figure 2 represents separated subsystems of the model which corresponding to components of hydraulic system i.e.: block of supply pump 4 , block of relief valve 5 , block of actuator 1 and 2, block of flow divider valve 3 , block of actuators load 9, etc. Block 10 is used to determine global parameters of the system, for example fluid parameters. Results of the simulations are displayed in block 11.

Signals between blocks are transmitted as singlevalued or as vector signal (bold line on the diagram). Values of constant parameters such as: fluid properties, pressure in pump supply line and cylinder tank line, were defined globally in block "Parameters". Parameters describing individual subsystems were defined locally inside. Variable values transferred between block input and output are shown in diagram as lines connecting blocks. Values of variable during simulation are shown on graph or if it is necessary might be save to ASCII file. It is possible thanks to transmission values by blocks "From" and "GoTo" to block "Results".

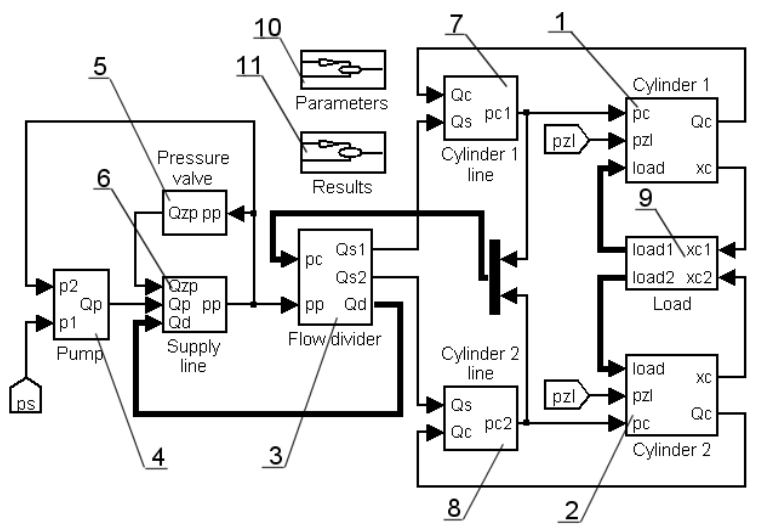

Figure 2. Simulink block diagram of model of the synchronization system: 1,2 - block of hydraulic actuators, 3 - block of flow divider valve, 4 - block of supply pump, 8 - block of actuator load

Hierarchic structure of the model is shown in Figure 3 . On the model tree we can see all subsystem and connections with external user libraries.

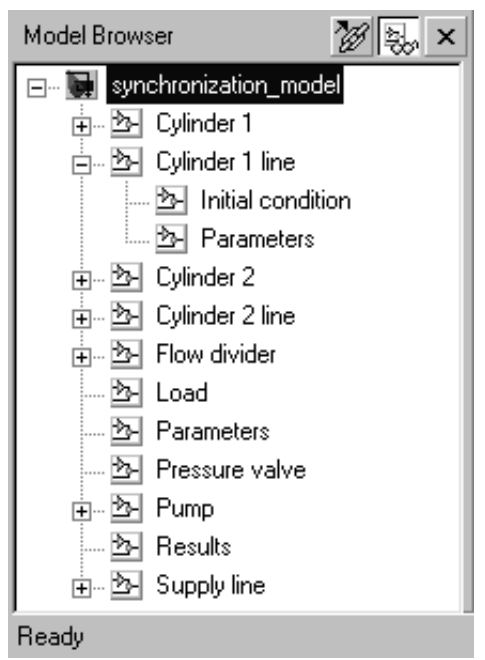

Figure 3. Structure of synchronization system model in Simulink

During modeling the lifting system own library of hydraulic drive and control component was used. The following models were used: model of pump with variable delivery, model of double acting hydraulic cylinder and model of two-stage relief valve. The use of models from library allows to modification whichever blocks automatically. The library built by the authors is still updating with new models, which are made according to mathematical models, experimental tests or static and dynamic characteristic. Mathematical model of the system with its equivalent Simulink block diagram is shown below. Coefficients in particular equations were set according to experimental tests. 


\subsection{Hydraulic pump}

Pump volumetric flow rate is described by formula:

$$
Q_{p}=q_{p} \frac{\omega_{p}}{2 \pi} \eta_{v p}
$$

where: $q_{p}-$ unitary pump delivery, $\omega_{p}-$ angular velocity of pump shaft, $\eta_{v p}-$ volumetric pump efficiency.

Volumetric losses are described by:

$$
\eta_{v p}=1-C_{v \mu} \frac{\left(p_{p}-p_{s}\right)}{\omega_{p}}-C_{v \rho} \frac{\sqrt{\left(p_{p}-p_{s}\right)}}{\omega_{p}},
$$

where: $p_{s}, p_{p}$ - pressure in inlet and outlet line, $C_{v \mu}-$ loss coefficient dependent on fluid viscosity, $C_{v \rho}$ loss coefficient dependent on fluid density.

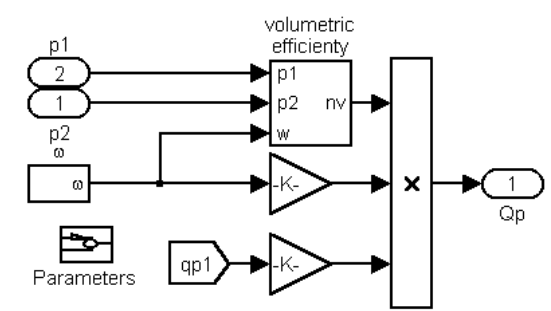

Figure 4. Block diagram of pump model

\subsection{Supply line pump-flow divider}

Fluid flowing to flow divider with volumetric flow rate $Q_{p}$ is divided into two flux with volumetric flow rates $Q_{d A}$ and $Q_{d B}$. For line with volume $V_{z}$ with substitute Bulk modulus $B_{z}$ equation of flow balance is:

$$
\frac{d p_{z}}{d t}=\left(Q_{p}-Q_{z}-Q_{d A}-Q_{d B}\right) \frac{B_{z}}{V_{z}}
$$

Block diagram equation (3) is shown in Figure 5.

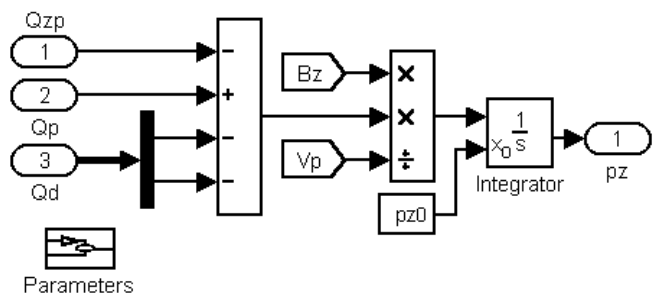

Figure 5. Block diagram of flow balance equation for supply line of the system

\subsection{Flow divider valve}

Simplified, functional diagram of the valve is presented in Figure 6.

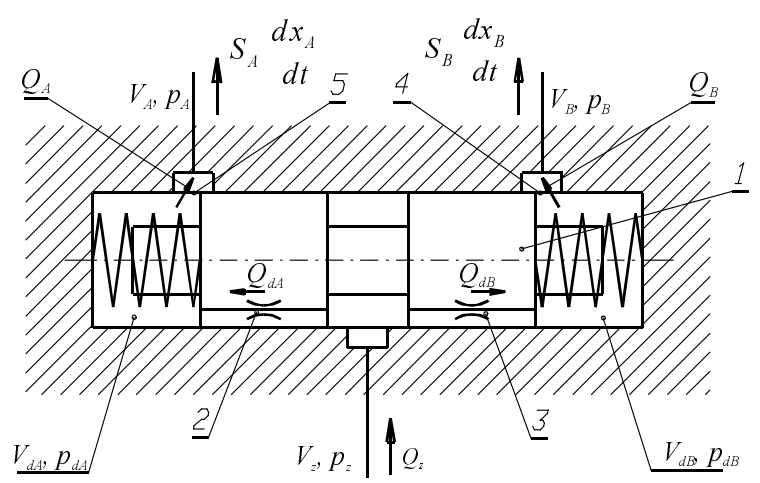

Figure 6. Schematic diagram of flow divider: 1 spool; 2, 3 - throttle nozzles; 4, 5 - throttle gaps

Structure and main block diagram of the flow divider model with block of flow equations spool motion, etc. is presented in Figure 7 and Figure 8.

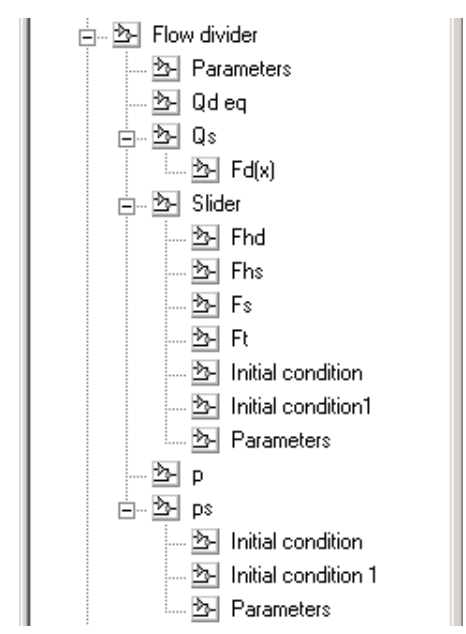

Figure 7. Structure of flow divider model

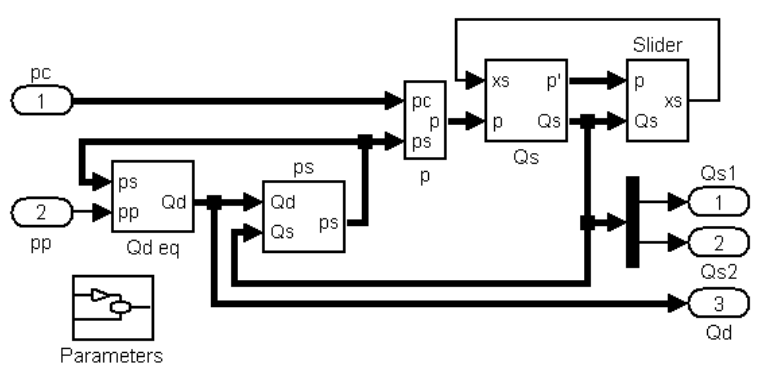

Figure 8. Block diagram of flow divider model

Volumetric flow rate through flow divider nozzles 2, 3 (Figure 6) we can describe:

$$
Q_{d A, B}=\mu_{d A, B} S_{d A, B} \sqrt{\frac{2\left(p_{z}-p_{s A, B}\right)}{\rho}},
$$

where: $\mu_{d A, B}$ - outflow coefficients for nozzles 1,2 , $S_{d A, B}$ - area of throttle nozzle, $p_{z}$ - supply pressure, $p_{s A, B}$ - pressure in chambers $V_{A}$ i $V_{B}, \rho$ - pressure in chambers. 
Figure 9 presents block diagram calculating value of fluid flow rate in chamber $V_{A}$ and $V_{B}$ of the flow divider.

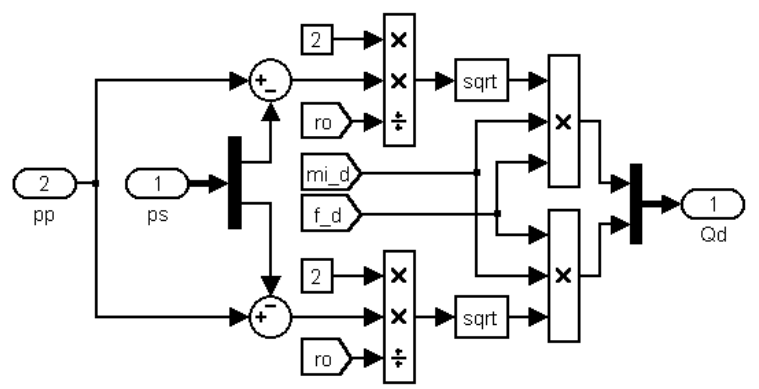

Figure 9. Block diagram of fluid flow through throttle nozzles

For individual valve chambers with volume $V_{A}$ and $V_{B}$ flow balance, considering fluid compressibility has been made:

$$
\frac{d p_{s A, B}}{d t}=\frac{B_{z}}{V_{A, B}\left(x_{s}\right)}\left(Q_{d A, B}-Q_{s A, B}\right) .
$$

Block diagram of equations $5 \mathrm{~A}$ and $5 \mathrm{~B}$ is shown in Figure 10.

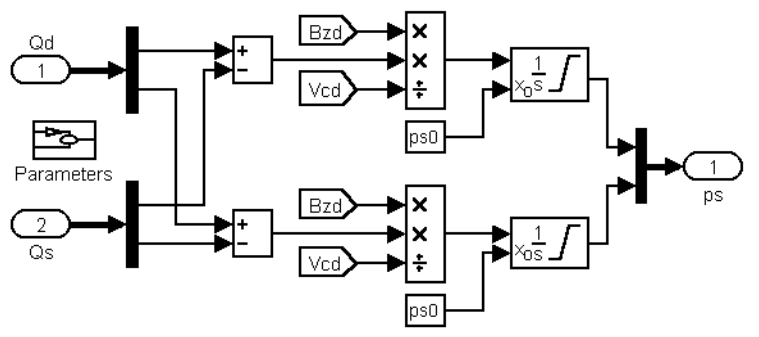

Figure 10. Block diagram of flow balance equations in flow divider chambers $V_{A}$ and $V_{B}$

The following forces act on spool with mass $m_{s}$ : hydrostatic forces, hydrodynamic forces, spring forces and force of viscous friction between bush and spool. Figure 11 presents forces acting on spool.

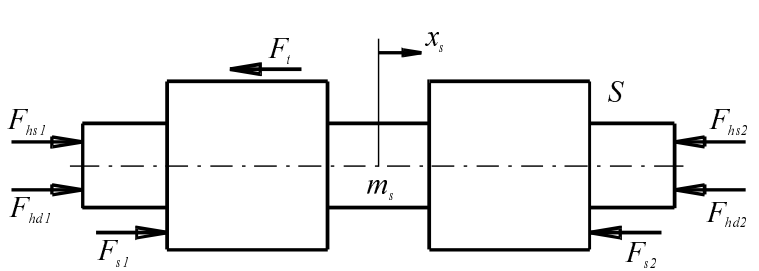

Figure 11. Forces acting on spool

Below there are forces acting on spool valve:

$$
\text { force of inertia } \quad F_{b s}=m_{s} \frac{d^{2} x_{s}}{d t^{2}}
$$

force of viscous friction $F_{t}=f_{s} \frac{d x_{s}}{d t}$,

spring forces

$$
\begin{aligned}
& F_{s 1}=c_{s}\left(-x_{s}+x_{w}\right), \\
& F_{s 2}=c_{s}\left(x_{s}+x_{w}\right)
\end{aligned}
$$

hydrostatic force

$$
F_{h s}=F_{h s 1}-F_{h s 2}=S\left(p_{s 1}-p_{s 2}\right)
$$

hydrodynamic force

$$
F_{h d 1,2}=0.36 Q_{s 1,2} \sqrt{2 \rho\left(p_{s 1,2}-p_{c 1,2}\right)} .
$$

Considering above equations the equation of spool motion has the following form:

$m_{s} \frac{d^{2} x_{s}}{d t^{2}}+f_{s} \frac{d x_{s}}{d t}+2 c_{s} x_{s}=F_{h s}+F_{h d 1}-F_{h d 2}$,

where: $x_{s}$ - spool displacement, $m_{s}$ - spool mass, $f_{s}$ coefficient of motion resistance, $c_{s}$ - substitute coefficient of springs stiffness, $S$ - active spool face.

The spool model with acting forces is presented in Figure 12.

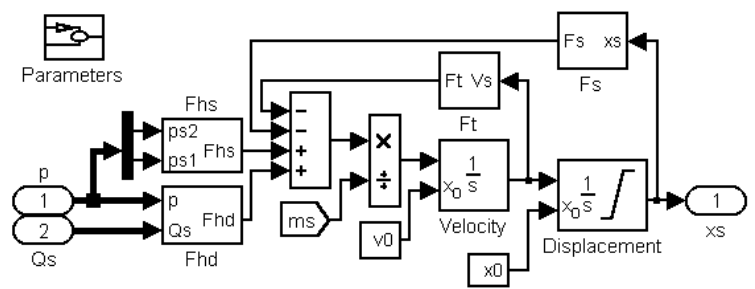

Figure 12. Block diagram of spool model

To cylinder lines flow fluid with volumetric flow rate $Q_{A}$ and $Q_{B}$ through gaps 4, 5 (Figure 6) for cylinder $\mathrm{A}$ and $\mathrm{B}$, respectively. The flow rate can be expressed by:

$$
Q_{A, B}=\mu_{A, B} S_{s z A, B}\left(x_{s}\right) \sqrt{\frac{2\left(p_{d A, B}-p_{A, B}\right)}{\rho}},
$$

where $S_{s z A, B}\left(x_{s}\right)$ - area of cross-sectional in function of spool position.

Block diagram of flow through throttle nozzles with variable cross-section is shown in Figure 13. 


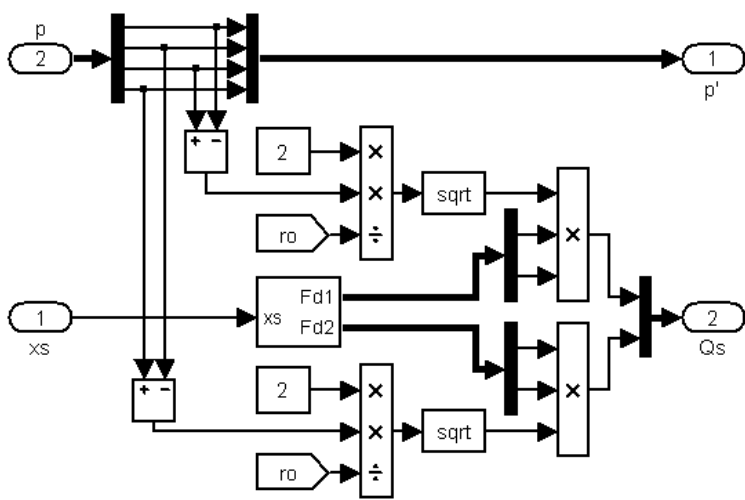

Figure 13. Block diagram of flow through throttle nozzles with variable cross-section

Input signals are values of pressure and spool position $x_{s}$, whilst output signals are volumetric flow rate in particular lines supplying cylinders.

\subsection{Cylinder supply line}

To cylinders line with adequate volumes $V_{A, B}$ flow fluid with volumetric flow rate $Q_{A, B}$ from flow divider valve, whilst quantity of fluid flowing out is dependent on piston rod velocity and areas of pistons $S_{A, B}$. It is described by equation:

$$
\frac{d p_{A, B}}{d t}=\left(Q_{A, B}-S_{A, B} \frac{d x_{A, B}}{d t}\right) \frac{B_{A, B}}{V_{A, B}},
$$

in which index $A$ concerns actuator 1 , whilst index $B$ concerns actuator 2 (Figure 1).

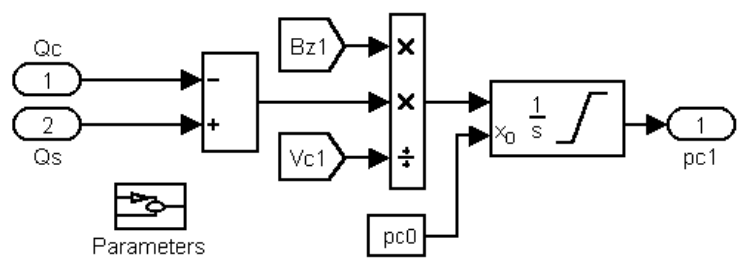

Figure 14. Block diagram of flow balance in cylinder 1 supply line

\subsection{Hydraulic cylinders}

Assuming that in the system alike cylinders were used, equations of piston rod have the following form:

$$
m_{A, B} \frac{d^{2} x_{A, B}}{d t^{2}}+\alpha_{A, B} \frac{d x_{A, B}}{d t}=\Delta F_{h s A, B}-F_{o b c A, B},
$$

where: $m_{A, B}$ - reduced mass into piston rods, $F_{o b c A, B}$ cylinders load, $\Delta F_{h s A, B}$ - difference of hydrostatic forces on both side of the piston.

Hydrostatic force in cylinder

$$
\Delta F_{h s A, B}=p_{c A, B} S_{c}-p_{z l} S_{c t},
$$

where: $S_{c}, S_{c t}$ - areas of piston (on both sides), $p_{c A, B}$, $p_{z l}$ - pressure in supply line and tank line.

Cylinder absorbing capacity describes following equation:

$$
Q_{c A, B}=S_{c t} \frac{d x_{A, B}}{d t}
$$

Block diagram of cylinder model described by equations (14), (15), (16) is shown in Figure 15. Input signals are: instantaneous values of pressures in cylinder supply and tank line and cylinder load. Forces acting on piston rod and instantaneous piston rod velocity and displacement are calculated in proper blocks.

Block "Parameters" contains constructional parameters of cylinder such as: diameter of piston ,piston rod, piston stroke and mass of moving elements. Initial piston rod velocity and displacement are transmitted to corresponding blocks of integrating piston rod motion equations. Output signals are: cylinder absorbing capacity and piston rod displacement.

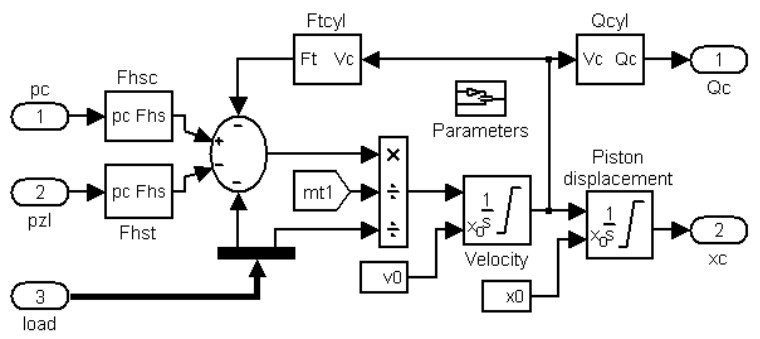

Figure 15. Model of double acting hydraulic cylinder with one-sided piston rod

\subsection{Components of the system}

Models of the rest of system components were also built, but they are not presented in this paper.

\section{SIMULATIONS}

In order to determine characteristic of analyzed system program Simulink 6.0 was used. To solve differential equations Runge-Kutta IV order method with variable step was used. Minimal integrating step was set as $\Delta t_{\text {min }}=10^{-6}$ with permissible relative error $\varepsilon_{m}=10^{-3}$.

Presented in Figure 1 system was undertaken a numbers of simulations. Flow divider in the system should divide fluid flux in a way ensuring the same piston rods displacements. Dynamic phenomena might be a cause of spool vibration and errors in flux dividing what influence on positioning errors.

In Figure 16 an exemplary courses of pressures and piston rod displacements were presented as a response of step function of volumetric flow rate $Q_{z}$ during lifting load $75 \mathrm{kN}$ distributed no uniformly 
with ratio $2: 1$ by assumption that volumes in line are: $V_{A}=1 \mathrm{dm}^{3}, V_{B}=3 \mathrm{dm}^{3}$.
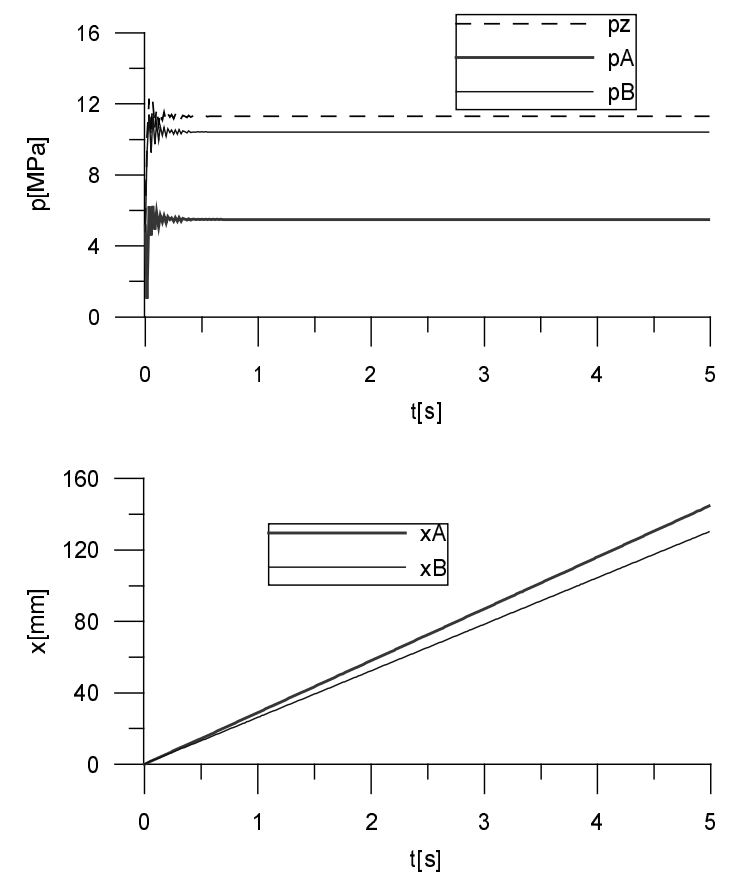

Figure 16. Courses of pressure and piston rods displacement: $p_{z}-$ on input to flow divider, $p_{A}-$ in cylider line $V_{A}, p_{B}-$ in line of cylinder $V_{B}$

Figure 17 presents courses of pressure and piston rods displacement as a response of step function of volumetric flow rate $Q_{z}$ with constant load $50 \mathrm{kN}$ for each cylinders. Additionally on cylinder $A$ was applied load of sinusoidal force $10 \mathrm{kN}$ with frequency $3 \mathrm{~Hz}$. Volume of hydraulic line were: $V_{z}=1,5 \mathrm{dm}^{3}$, $V_{A}=1 \mathrm{dm}^{3}$ and $V_{B}=1,2 \mathrm{dm}^{3}$.
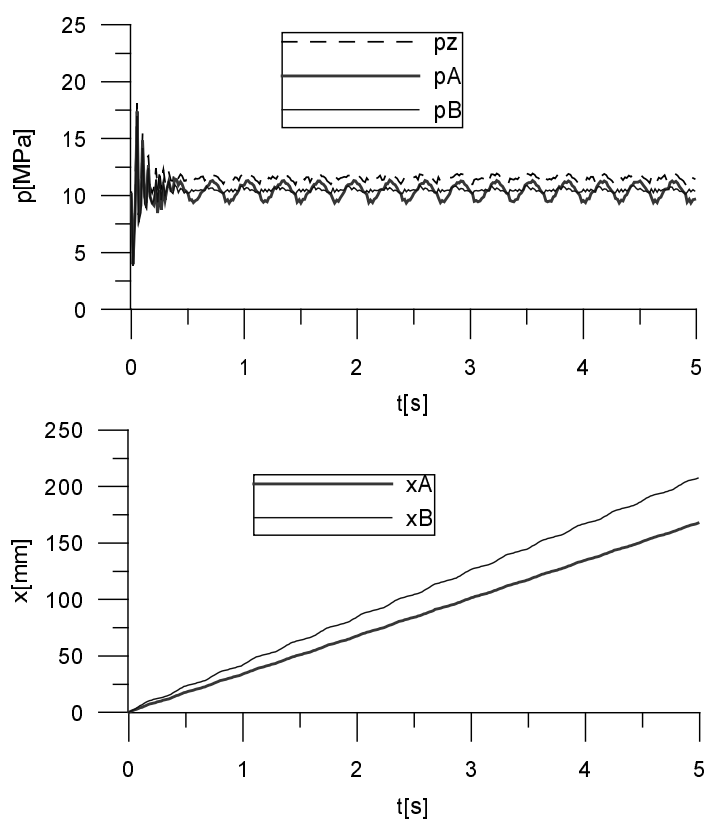

Figure 17. Courses of pressure and piston rods displacements: $p_{z}-$ on input to flow divider, $p_{A}-$ in line of cylinder $V_{A}, p_{B}-$ in line of cylinder $V_{B}$

\section{SUMMARY}

The way of obtaining static and dynamic characteristic of hydraulic cylinder synchronization system, which is presented in this work allows to determine influence of constructional parameters on flow characteristic and positioning accuracy. Those parameters are: shape and dimension of throttle nozzles, spring stiffness, spool motion damping, volumes of valve chambers etc. It allows to specify constructional guidelines for flow divider valve.

To test this kind of system a test stand was built in the Institute of Heavy Duty Machines of Cracow University of Technology. It allows to comparison experimental test with simulations.

\section{REFERRENCES}

[1] Kollek W., Palczak E.: Optymalizacja elementów układów hydraulicznych. Ossolineum, Wrocław 1994.

[2] Lisowski E., Brandys P.: Research of flow divider valve in a hydraulic cylinders synchronization system. 2nd International Scientific Forum „Developments in Fluid Power Control of Machinery and Manipulators", Fluid Power Net Publication, Cracow 2000.

[3] Brandys P., Lisowski E.: Stanowisko do badania synchronizacji ruchu siłowników hydraulicznych, XII Konferencja Naukowa „Napę, sterowanie, automatyzacja maszyn roboczych i pojazdów", Rynia k/Warszawy 2000. 